\title{
Book reviews 2015
}

DOI 10.1515/ntaxj-2015-0013

Received Feb 09, 2016; accepted Feb 19, 2016

\begin{abstract}
This section contains three book reviews. First the book Swedish Taxation, Development snice 1862 is reviewed. This volume comprises six studies that examine the development of Swedish taxation from 1862 to 2013 , and will likely be of great value in future Nordic tax research because of its comprehensiveness. The second review is about a book written in Swedish: Momsfri sjukvård (The VAT exemption for health care). This volume discusses a topical issue and presents convincing recommendations for changes in the Swedish VAT legislation. Finally, the Danish book International Skatteret, i et dansk perspektiv (International Tax Law, in a Danish perspective) is presented as highly recommended literature for students and practitioners in the field of international tax law. This volume discusses and illustrates general matters in international tax law, as well as specific matters relevant for Danish international tax law.
\end{abstract}

\section{Swedish Taxation, Developments since 1862}

\author{
Palgrave Macmillan, 2015, 334 pages \\ Authors: Edited by Magnus Henrekson ${ }^{1}$ and Mikael \\ Stenkula²
}

Reviewer: Peter Melz ${ }^{3}$

This book covers the development in Sweden since 1862 of all major tax forms; Labor Income Taxation, Capital Income Taxation, Taxation of Goods and Service, Inheritance and Gift Taxation, Wealth, Taxation and Real Estate Taxation. In each field, the tax burden is calculated in a

Edited by Axel Hilling: Associate Professor of Tax Law, Lund University School of Economics and Management, Sweden

1 Professor of Economics and President of the Research Institute of Industrial Economics, Sweden.

2 Research Fellow at the Research Institute of Industrial Economics, Sweden.

3 Professor of Financial Law, Stockholm University, Sweden. number of ways for each of the years the tax has been in force. Total payment of a tax is compared to total tax revenue and/or the GDP for the year. In a number of examples, the tax burden is calculated for taxpayers in a certain situation or marginal taxes are calculated more generally.

The volume of statistics calculated and presented is impressive. As the authors state, the book is unique as such a comprehensive presentation of the development of taxation in Sweden has not been presented before. I even doubt that there is something like this for other countries. The compilation and calculation behind the information is thorough and must have been an enormous job for the authors, especially as only one assistant is mentioned and thanked. In the foreword, the contributions of Gunnar Du Rietz is especially emphasized. He has a long experience in the field of tax statistics.

The structure of the chapters is to a great extent the same. First, the structure and development of relevant tax rules are described. As there have been numerous changes in most fields, this is a huge task. The authors have had help of tax history described in a number of sources, but for a comprehensive description, a vast amount of primary material must have been studied as well. Some sections of reference include a large number of primary material, but others do not include all relevant primary material such as statutes. Probably, this is because good secondary sources have been available in the latter case. Based on my personal knowledge, which is not complete, my impression is that the descriptions are thorough and reliable.

Second, tables of tax rates are calculated for different periods. In some chapters these are so long that they have to be presented in appendices.

From theses tables, a number of calculations are made and illustrated in figures. For instance, in the chapter of Labor Income Taxation, marginal tax wedges of income are calculated. They are calculated based on marginal income tax rates and marginal employer- and employee-paid SSC. Economists are more keen on acronyms than lawyers. Since there is no list of abbreviations when reading a figure, you may have to spend some time going backward in the text to find the definition of the acronym. Well, I could guess out of the context that SSC means social security contributions. I am less sure that I understand exactly how APW is calculated, which is used as a measure to show the marginal tax rate and so on of different income levels. At 
page 38, I find that APW means average annual wage of a production worker.

In some chapters, the calculations are limited to the tax revenue of specific taxes, for example, consumption taxes, compared to total tax revenues.

It is a too huge task to present even some of the results in the book. One could only remark that as some results are not a surprise such as a high taxation of labor income since the beginning of 1970, others are more surprising such as all complicated forms of taxation of corporations. But the results need to be studied in the book not presented here.

This is not a book of which you will read every page in detail. This is a reference work for future studies and will give a valuable head-start for many researchers. There will be a number of different ways to use it. For academic lawyers, access is given to a fuller background of developments in their field of studies. A lot of law studies may be into specialized questions that are not covered of the broader development of tax rates and so on presented in the book. But even in such cases, one will find useful information. For instance, if you are interested in taxation of charitable foundations, it is of interest to study also the height of gift, inheritance, and wealth taxation for different years, as these were taxes that could be avoided by creating a foundation.

But most useful will the information in book be for economists who will use it for further analysis. The conclusions in the book consider mainly the development over time of the taxes and the various measures for METR and so on applied. The field is left open for economists who want to draw further conclusions about how the development of different taxes has had impact on the economy and society at large.

And then they will be grateful that all these collection, compilation, and analysis of the tax structure for 150 years have been made.

\section{Momsfri sjukvård}

\author{
Iustus, 2015, 208 pages \\ Author: Robert Påhlsson ${ }^{4}$ \\ Reviewer: Henrik Stensgaard ${ }^{5}$
}

According to the preface, the purpose of the book 'Momsfri Sjukvård' is to carry out a jurisprudential study of the Value Added Tax (VAT) exemption of medical care. The book is intended for use in an academic context, but also for the use of legislators and practitioners. As often seen, in relation to books of this kind, it has a double perspective: First, an analysis of EU law, including the EU VAT Directive and the case law of the European Court of Justice, is carried out and then national legislation and, for example, national case law are examined with a view to identify whether these are in accordance with EU law.

The topic of the book is both of current interest and relevant for several reasons. As also pointed out by the author, the VAT exemption of medical care has undoubtedly received far greater importance in recent years as far more of the relevant medical treatments are carried out in the private sector, including at private hospitals. Thus, in principle, these private actors must decide for each of the performed treatments whether they are covered by this VAT exemption or not. In addition, the European Court of Justice has decided a large number of cases in this field, which deserve a more detailed and comprehensive analysis.

The book has a legal dogmatic aim and the idea is thus not to propose improvements to the current system at a more principle level. The book also has a strong Swedish perspective. On page 21, it is thus stated that the EU law material is dealt with on the basis of the Swedish-language versions. This approach, however, may result in hasty conclusions as interpretational problems in relation to one linguistic version often can be clarified by consulting other linguistic versions. The author is, however, aware of this fact and includes other linguistic versions where necessary.

EU law is dealt with in part I of the book (pp. 17-136). Chapter 1 contains an introduction, Chapter 2 contains a presentation and an analysis of the relevant provisions of the EU VAT Directive, while Chapter 3 contains an analysis of the case law of the European Court of Justice. The intro-

\footnotetext{
4 Professor of Tax Law, University of Gothenburg School of Business, Economics and Law, Sweden. 5 Professor of Tax Law, Aarhus University, Denmark.
} 
ductory Chapter 1 could, with advantage, have been separated from part I, as, in reality, it serves as an introduction to the book as a whole.

In Chapter 2, the author has chosen to carry out a preliminary analysis of the relevant provisions of the EU VAT Directive. Thus, this applies for articles 131, 132, 133 and 134. In this connection, focus is both on the mandatory and the optional conditions that are specified in the Directive with respect to the VAT exemption. The separation of these terms and conditions is subsequently controlling the structure both in Chapter 3, where the case law of the European Court of Justice is analyzed, and Chapter 4, where Swedish legislation and, for example, case law are presented and assessed in the light of EU law. This structure works very well as it provides the reader with an overview of the legal issues relevant in connection with both the implementation as well as subsequent application of the law.

First, the author mentions article 131 of the VAT Directive. As pointed out by the author, it is a very general provision, which gives rise to doubts about the scope of the competences left to the member states. The European Court of Justice has, however, on a number of occasions interpreted article 131, whereby the legal limits of the provision have been laid down in further detail. Here, the author could, for example, have referred to case C-124/96, Commission v Spain, and Case C-498/03, Kingscrest.

In the mentioning of article 134 on page 39f, the author seems to distinguish between the two conditions set out in items a and b, respectively. Item $a$ is regarded as being related to transactions closely related to the VAT-exempt transactions according to article 132, while item b is regarded as a general provision in relation to all the transactions that would otherwise be exempt from VAT in article 132. This view cannot be endorsed. In article 134, reference is only made to VAT exemptions in article 132, items $\mathrm{b}, \mathrm{g}, \mathrm{h}, \mathrm{i}, \mathrm{l}, \mathrm{m}$ and $\mathrm{n}$, which are exactly the VAT exemptions, which also exempt activities closely related to the transactions in question. Article 134, items a and b, are therefore to be regarded as cumulative conditions in order to be able to exempt transactions closely related to the VAT-exempt transactions. This view is supported by the rhetoric of the European Court of Justice in joined cases C-394/04 and C395/04, Ygeia, paragraph 35 and case C-415/04, Stichting Kinderopvang Enschede, paragraph 29.

In Chapter 3, a very interesting analysis of the case law of the European Court of Justice in the area is carried out with a view to identify the exact meaning of the concepts and so on, which are used in the VAT Directive. In addition, the ambition is to identify the more general trends in the interpretation carried out by the European Court of Justice. This applies for, for example, the statement on VAT exemptions that they must be interpreted in a restrictive way. As a rule, this must be assumed to mean that an interpretation of the VAT exemptions should be less extensive than a straightforward and natural reading of the wording at first appears to give rise to. However, when one observes the overall case law of the European Court of Justice in the area of VAT exemptions, it seems difficult to see the trend towards narrowing down the scope of VAT exemptions in this way. The statement of the European Court of Justice about a restrictive interpretation of VAT exemptions, may thus, alternatively, just be taken to mean that analogies are ruled out, see, for example, case C-269/00, Seeling.

At page 51ff, the book contains a relatively extensive presentation and analysis of the multi-faceted principle of neutrality. The section is quite interesting and contains many interesting reflections, including the principle's relationship with the principle of equality. The author demonstrates, among other things, that the principle plays a major role in the interpretation.

In connection with the analysis of the central concepts of the VAT exemptions, it is found that in the Swedish version of the Directive in art. 132 items b and c, respectively, various concepts are used to define the services that are exempt from VAT inside and outside the hospital sector. The same is also apparent in the Danish version of the Directive. A varied application of the concepts naturally gives rise to doubts as to their meaning. If, on the other hand, one turns to the English version of the Directive, it may be ascertained that in both items $\mathrm{b}$ and $\mathrm{c}$, the term 'medical care' is used. On page 126, the author therefore gives fair criticism against the wording of the Swedish Directive. The use of different concepts in items b and c, respectively, gives completely unnecessary rise to doubts as to its meaning. As a consequence, it is therefore de facto in case C384/98, D, that the European Court of Justice for the first time concludes that VAT exemption only applies if a therapeutic aim is present.

At page 90, the author has a very interesting discussion of the relationship between the concept of 'closely related activities' and the general theory on mixed transactions. It is thus considered whether the concept 'closely related activities' is entirely a pedagogical reminder of the theory on mixed transactions. This discussion is raised in continuation of case C-366/12, Klinikum Dortmund, in which the European Court of Justice finds that subordinate, but absolutely necessary deliveries can be exempted from VAT in accordance with item c, and the author briefly considers whether this is an expression of the general theory on mixed transactions. This is an extremely interesting question, which, however, on the basis of the present case 
law of the European Court of Justice, must be deemed to remain open.

At page 129, the author raises the interesting question of whether EU law sets requirements for the quality of the treatments that are covered by VAT exemption. This question is, for example, relevant in relation to item c, where member states have an authority to define the medical and paramedical professions that are covered by this VAT exemption. In Danish law, there have often been reasons for considering this question as the Danish tax authorities have not explicitly made such a requirement in their acknowledgement practice. The author's legitimate conclusion is that EU law contains such requirements that particularly is manifested in joined cases C-443/04, Solleveld and C-444/04, van Eijnsbergen. The European Court of Justice obviously does not specify the requirement in further detail. This must be left to the experts in the area.

In part II of the book (pp. 139-196), the legal status in Sweden is discussed. This part only consists of Chapter 4, in which an overall analysis of both the implementation and the Swedish case law in courts and administrative bodies is carried out. One of the main purposes of the chapter is to explore the relationship to EU law, which is analyzed in the previous chapters.

First, the author discusses the importance of the national preparatory works. In relation to areas regulated by EU law, there may be a tendency to disregard any national preparatory work. As correctly pointed out by the author, national preparatory work might still play a role in areas where a directive delegates competence to the member state. This is certainly the case for the VAT exemption of medical care. In addition, it is pointed out that preparatory work, even in areas where no competence is delegated to the member state, can play a role as an inspiration to a sustainable legal argumentation. This inspiration, however, can only be accepted if the result of the interpretation can be considered as a plausible forecast of a future decision of the European Court of Justice.

When Sweden joined the EU in 1995, the legislator chose to continue the former Swedish legislation in relation to VAT exemption of medical care without changes. It goes without saying that this entails a great risk of creating legal differences already in the implementation phase. When the language differences between the Directive and the national legislation are significant, it will, however, also impose a great risk for the subsequent application of law at the national level, as this application might deviate from EU law, including the case law of the European Court of Justice. Swedish legislation, for example, contains its own definition of medical care, which cannot take account of the changes and nuances that arise in connection with new case law from the European Court of Justice. It is, however, the author's overall conclusion that the Swedish VAT Act still can be subject to an interpretation consistent with the EU VAT directive.

The author directs a sharp criticism against national case law and against the guidelines of the tax authorities, in particular. On page 165 , it is thus stated that the guidelines have not adequately taken account of the fact that Sweden became member of the EU more than 20 years ago. In addition, it is established that the opinions of the tax authorities in a number of cases are misleading and characterized by an incorrect application of the sources of law.

In relation to 'activities closely related' to the VATexempt transactions, it is, in general, the author's opinion that Swedish legislation exempts transactions from VAT to a too large extent and, as a result, should be changed. The present design of the Swedish VAT legislation gives taxpayers an opportunity to invoke the Directive if they prefer VAT liability and to invoke the law if they prefer a VAT exemption.

Overall, this is without doubt an interesting book worth reading, and it clearly lives up to its purpose. Consequently, there is no doubt that the analysis carried out will be useful for the legislator as it contains clear recommendations for changes in the Swedish VAT legislation. The tax administration in Sweden and also, practitioners, in general, could benefit greatly from reading the book.

\section{International skatteret - I et dansk perspektiv}

\section{Hans Reitzels Forlag, 2015, 439 pages Authors: Peter Koerver Schmidt ${ }^{6}$, Michael Tell ${ }^{7}$ and Katja Dyppel Weber ${ }^{8}$ Reviewer: Lars Kjærgård Terkilsen ${ }^{9}$}

This book, which has been written by most of the members of the tax law group at Copenhagen Business

\footnotetext{
6 Assistant Professor, Law Department, Copenhagen Business School, Denmark.

7 Associate Professor, Law Department, Copenhagen Business School, Denmark.

8 Associate Professor, Law Department, Copenhagen Business School, Denmark.

9 Associate Professor PhD, Department of Law, University of South-
} ern Denmark, Denmark. 
School, is intended to be used as a student text book on international tax law.

According to its preface, the aim of the book is to provide a thorough, up-to-date and accessible presentation of international tax law from a Danish perspective. The aims of being thorough and up-to-date are common to many academic books, but the ambition of accessibility is less common. However, accessibility is a highly desirable quality in a student textbook for use on international tax law courses.

The three authors write that their approach to the book has been inspired by the periods of research each of them has spent at different American universities, where they found that, to a greater degree, the textbooks used encourage the (student) reader to prepare actively for courses in international tax law. As a result of this inspiration, the authors intend the book to promote the benefits to students of preparing for classes. True to this intention, each chapter of the book makes extensive use of cases, examples, and figures.

The layout of the book is also intended to encourage its use for study. Students will be encouraged to use the book by the care that has gone into its presentation and production.

For teachers using the book for their courses, a teaching plan with additional literature can be downloaded from the publisher's website. In this way, the book should be instructive for teachers as well as students.

The book is divided into four parts:

1. Introduction and sources of law

2. Tax treaties and relief from double taxation

3. EU tax law

4. Tax planning and anti-abuse regulations.

The content of the book has not been rethought in the same way as its presentation as the purpose of the book is to serve as a textbook for courses in international tax law at Danish universities and business schools. However, the structure of the book's four parts differs from that of existing books on the market.

Parts 1-3 deal with the three dimensions of international tax law; national regulation, tax treaties, and EU tax law. Part 4 focuses on various aspects on international tax planning. After introducing the basics in the first three parts, the fourth part brings all three dimensions into play as the concept of tax planning is introduced and different types of anti-abuse regulations relating to the three dimensions are presented.

In short, this is a text book that deals with the classic issues of international tax law such as full and limited liability to tax, the relationship between national reg- ulations and tax treaties, as well as more modern aspects such as various kinds of anti-avoidance rules. However, the book's layout and the presentation of the material is, by no means, the classic approach of Danish international tax law text books.

First of all, it is to be mentioned that the authors succeed in their aim with the book.

The book is divided in 12 chapters, with each chapter following the same template. After the presentation of the topic, each chapter contains a number of questions for self-assessment, a case study, endnotes, and a list of suggested further reading. In line with many US text books, this enables the reader to follow up on and assess their understanding of the chapter.

Another aid to getting an overview of the topic is that every section of the book has a heading in the margin enabling the reader to get an easy overview of the content of each section. This will be a great help for both the student looking to refresh their memory of what they have read and for practitioners looking up a specific point. This serves to fulfill the aim of the book.

Chapter 1 (Introduction to international tax law) introduces the reader to international tax law in general. The basic concepts of international tax law, such as the principles of global and territorial income and double taxation are presented together with a short presentation of the different sources of law and the relationships between the three dimensions.

The presentation is quite dense, which has the benefit of presenting a lot of material in a few pages. However, in places one could have wished for a more discursive presentation. Of course, it can be argued that a text book is not supposed to burden its readers with extensive discussions of more theoretical aspects of its subject. However, when a discussion has an important impact on the use of the rules, this should be noted. Since a thorough introduction to the methodology is of great importance when presenting a new topic to students, the book would have benefited from more detailed discussions of methodology in this chapter. This is no less important when dealing with the multitude of sources of international tax law.

On page 24, the interpretation of tax treaties is presented with reference to the Vienna Convention. The section includes a presentation of the pacta sunt servanda principle of international law as well as the delimitation between primary and supplementary means of interpretation. It would have been interesting if the authors had presented their views on how the sources of international tax law were to be placed in this context.

The section ends by noting that the use of the Vienna Convention has been the subject of significant interest in 
tax literature. Here, it would have been helpful if it had been presented what the discussions in the literature were about.

One could also have wished for a more detailed discussion of the relationship between national tax regulations and tax treaties, as well as EU law. The distinction made between dynamic and static interpretation on pages 25-26 ends with a reference to the distinction between 'changes' and 'specifications' in the Model Tax Convention and the impact of the use of new wording on the interpretation of existing tax treaties. It would have helped the reader if there had been a discussion of the criteria used to determine whether different wording is a 'change' or a 'specification'.

Chapter 2 (Full and limited liability to tax) presents the Danish regulations on full and limited tax liability of individuals and corporations.

Part of section 2.2 on the tax liability of companies gives a presentation of the Danish legislation on the taxation of corporate groups. A lack of references to case law and administrative decisions impairs the discussion. For instance, on p. 51, the definition of 'decisive influence' in section $31 \mathrm{C}$ of the Danish Corporate Tax Act is presented without any reference to the cases on this topic.

Chapter 3 (Double taxation and relief) introduces the reader to the concept of tax treaties with an emphasis on the allocation of taxing rights, the scope of tax treaties, and the various forms of relief from double taxation. The presentation of the forms of relief from international double taxation, in particular will doubtless be enthusiastically received by students as it gives a high level of clarity together with some well-chosen examples of the calculation of relief, contributing to an understanding of the issues.

Chapter 4 (Salaries and other personal income) deals with the allocation of the right to tax salaries and other personal income. The chapter includes some easily understood models and figures illustrating the various distinctions that must be made when dealing with the allocation of the right to tax personal income. The chapter deals with all six types of personal income covered by the Model Tax Convention; income from private employment (including the rules on the international hiring out of labor), income from government service, directors' fees, entertainers and sportspersons, students, and pensions.

Section 2.1 of the chapter deals with the difficult question of taxation of international hiring out of labor. Even though one could wish for some references to case law, the section is a good example of how the authors succeed in presenting a difficult topic in a very clear manner.

Chapter 5 (Immovable property, permanent establishments and ships and aircraft) presents Articles 5-8 of the
Model Tax Convention. The focus on permanent establishments (PEs) is well chosen. Apart from a solid presentation of the definition of a PE, the reader is also given an easily understandable survey of the allocation of income to PEs. The extensive use of examples gives the reader a practical insight into the tax consequences of the use of different allocation rules.

Chapter 6 (Dividends, interest, royalties, and capital gains) deals with Articles 10-12 and 21 of the Model Tax Convention. The chapter includes a good discussion of the current debate on the concept of beneficial ownership.

Chapter 7 (EU harmonisation) deals with EU tax law. The chapter deals with both the fundamental freedoms of the TFEU, the prohibition of state aid as well as the directives on taxation. As the authors state on page 221, the EU has only harmonized direct taxes in the EU to a limited extent. It can be argued that this should have been clearer in the outline of the chapter. In particular, the section on the prohibition of state aid is quite short. It would have been interesting if the authors had given the reader a view on the use of the selectivity test compared with the restriction/discrimination approach when dealing with the fundamental freedoms.

It would also have been an advantage if the short presentation of the EU Court of Justice had included some discussion of the role of the Advocate General. Since some students of international tax law may not necessarily be familiar with general EU law, a more detailed presentation of the EU system might be appreciated.

A great advantage of the EU chapter is that it is highly topical. It is nice to see a presentation of EU tax law that deals with current issues, such as whether nondiscriminatory but restrictive tax rules breach the fundamental freedoms (p. 226). It is also nice that there are references to several of the newer cases from the EU Court of Justice. The relationship between EU law and the tax treaties is dealt with in the final section of the chapter.

Chapter 8 (International tax planning and anti-abuse regulation) shares its title with Part 4 of the book. It introduces the reader to international tax planning and the use of anti-abuse regulations in national and international law. The chapter gives an excellent presentation of a difficult topic - and a topic that is hard to be introduced to as a student. It is evident that, in addition to their academic credentials, the authors have extensive practical experience of this area to draw on. The reader is treated to views on both tax competition and the rationales behind tax planning as well as being given some well-chosen examples of how tax planning can be carried out - and how states try to combat it. 
Chapter 9 (Transfer pricing) gives the reader a thorough and clear presentation of this difficult topic.

Chapter 10 (Interest deduction limitation), Chapter 11 (CFC taxation) and Chapter 12 (Qualification and allocation conflicts) give examples of international tax planning and the anti-abuse rules used to prevent it. These chapters use the same template to present the rationale behind a regulation, the application of the regulation, and finally, the relationships between national provisions, tax treaties, and EU law.

The points made above do not detract from this reviewer's general view that this book on international tax law can be highly recommended. Students who follow courses in international tax law, while reading this book, can, unquestionably, be confident that they will be able to obtain a good introduction to the world of international tax law and, while the preface does not say that the book is aimed at practitioners, many practitioners will also gain by reading the book. 